\title{
The merits of Neo-Downsian modeling of the alternative vote: A reply to Horowitz
}

\author{
Jon Fraenkel · Bernard Grofman
}

Received: 5 June 2006 / Accepted: 22 February 2007 / Published online: 11 July 2007

(C) Springer Science + Business Media B.V. 2007

\begin{abstract}
In Professor Horowitz's rejoinders (2004, 2006) to Fraenkel and Grofman (2004, 2006a), he mischaracterizes our formal results, retreats from previous claims about the conditions for the alternative vote electoral system to generate centripetal outcomes, renders explicit his dubious assumptions about voter behavior in divided societies, and greatly exaggerates the global evidence in support of pro-moderation outcomes under the alternative vote. Here we respond to Horowitz's (2004), criticism in this journal of the formal model of Fraenkel and Grofman (2004) and to the broader defense in Horowitz (2006) of majoritarian vote pooling arrangements as means of mitigating ethnic conflict in deeply divided societies.
\end{abstract}

Keywords Elections $\cdot$ Voting $\cdot$ Social choice $\cdot$ Alternative vote $\cdot$ Ethnic conflict $\cdot$ Fiji

We can analyze the political consequences of institutional rules by investigating historical and cross-national evidence and/or by formally modeling the incentive structure and conditions that render different outcomes more or less likely. In recent work, the present authors (singly, and with various co-authors) have looked at the properties of preferential voting methods such as the single transferable vote (STV) and its single seat variant, the alternative vote (AV) ${ }^{1}$ from both a theoretical and an empirical perspective (Bowler \& Grofman, 2000; Fraenkel

We are indebted to Clover Behrend-Gethard for bibliographic assistance.

\footnotetext{
${ }^{1}$ The alternative vote may be considered a special case of the single transferable vote (see discussion in Bowler \& Grofman, 2000). Under the alternative vote, a preferential electoral rule to pick a single winner better known in the United States as the instant runoff, voters are required to rank order candidates. If no candidate has a majority of first place votes, the candidate with the fewest first place votes is dropped and that candidate's votes transferred to the next alternative on the voter's list. If none is found the process continues until we get a majority of first place preferences to one of the remaining candidates.
}

\section{J. Fraenkel}

Australian National University, Canberra, Australia

e-mail: jon.fraenkel@anu.edu.au

B. Grofman $(\bowtie)$

University of California, Irvine, USA

e-mail: bgrofman@uci.edu 
2000, 2001a; Grofman \& Feld, 2004; Regenwetter, Grofman, Marley, \& Tsetlin, 2006). In our joint work (Fraenkel \& Grofman, 2004, 2006a,b), we have focused on the alternative vote in situations where the major political cleavage in the society can be seen as an ethnic one. Our work on AV has had both a theoretical component, where we examine the formal properties of AV under carefully specified assumptions (Fraenkel \& Grofman, 2004), and an empirical component, where we look at results of the 1999 and 2001 elections in Fiji under the alternative vote (Fraenkel \& Grofman, 2006a). Fiji is a setting involving essentially bipolar ethnic conflict between native Fijians and Indo-Fijians (the descendants of Indians brought to the Pacific Islands by the colonial state).

Using a simplified formal model involving ethnic competition between two groups (with each group's support divided between a more moderate party and a more radical party), and with voters posited to have single-peaked preferences over a bipolar ethnic conflict dimension, we showed that both moderate and polarized outcomes are possible under an AV system (Fraenkel \& Grofman, 2004). Even if there is a moderate ethnic party that is the choice of the median voter in a constituency, the alternative vote will not always guarantee the selection of that party. We set out the specific conditions necessary for the alternative vote to select a Condorcet winner and suggested that they will not always be met in real-world settings. $^{2}$

Our work has challenged research by an influential theorist of constitutional democracy and ethnic conflict, Donald Horowitz, who has strongly advocated the use of the alternative vote in ethnically divided societies on the grounds of its moderation-promoting properties. Horowitz's advice about the role the alternative vote could be expected to play as a tool for mitigating ethnic conflict inspired a Constitutional Review Commission to recommend the adoption of AV in Fiji in 1997, and he continues to push for its adoption in other places where there is major ethnic conflict. Because our results conflict with some of his theoretical claims about the desirable properties of AV, Horowitz has been rather insistent that we are wrong. He responded to our modeling work on AV in Public Choice with a rejoinder essay in this journal (Horowitz, 2004), and he has responded to our empirical work (Fraenkel \& Grofman, 2006a) on how AV actually worked in Fiji in the elections of 1999 and 2001 with a critical essay in Comparative Political Studies (Horowitz, 2006).

We have had the opportunity to offer a rejoinder to Horowitz's attack on our analyses of 1999 and 2001 Fiji election data, although this was limited to a brief discussion of the empirical and Fiji-specific components of our work (Fraenkel \& Grofman, 2006b). Here, we offer first a response to Horowitz's (2004) criticisms of our characterization of AV's theoretical properties (Fraenkel \& Grofman, 2004) and, second, a discussion of Horowitz's broader defense of $\mathrm{AV}$ as a tool for electoral engineering.

First, Horowitz suggests that our model requires that voters "transfer no votes interethnically until it is no longer possible for a voter to give a preference to a party of his own group" (2004:509, 514). That simply mischaracterizes our assumptions. In our modeling, we distinguish between "severe" and "mild" preference schedules: in the latter, moderates of the two ethnicities initially exchange preferences across ethnic lines; in the former, exchanges of preferences initially are intra-ethnic. We, in fact, allow for both types of preferences (see Figure 1 and Table 1 in Fraenkel \& Grofman, 2004). Horowitz now insists that "mild," rather than "severe," preferences are the key presupposition of his theory as regards the centripetal impetus of AV. In so doing, he in fact concedes our major point, and reveals some

\footnotetext{
${ }^{2}$ As is well known, when voters have single-peaked preferences there will always exist a Condorcet winner (Black, 1958). 
questionable assumptions in his previous work regarding voter behavior in deeply divided societies. $^{3}$

In the four party model with no party obtaining a majority at the first count, if preferences are predominantly "severe," the AV system is much more likely to have centrifugal, rather than centripetal, effects. Outcomes are more likely to favor moderates if ethnic preferences are "mild." As we have argued (Fraenkel \& Grofman, 2004), for AV to work consistently in favor of moderation, Horowitz presupposes a significant degree of voter support for moderate parties, either at first preference-level or by voters having what we have referred to as mild preferences.

Secondly, Horowitz asserts that, by using examples in which voters have severe preferences, we are "poorly grounded in the literatures on ethnic politics and voting" (2004:509). Assumptions of "severe" preferences are held to be "far more hard-line than the behavior of voters in divided societies," whereas Horowitz's view that mild preferences should be found is to "utilize assumptions corresponding to actual behavior" (2006:654; 2004:511). We strongly disagree.

Empirical evidence from divided societies gives us much more reason to expect severe preferences than mild ones. As Laponce recognized, "if the political parties are built along communal lines, it is very doubtful that the different choices of an elector will go from the candidates of one community to that of the other. The distribution of secondary choices will tend to be among parties or candidates of the same community" (Laponce, 1957:327). In bipolar Northern Ireland, where STV was reintroduced in 1973, early hopes that preference transfers would favor centrist parties were disappointed. In the two elections for the new power-sharing Assembly following the 1998 Good Friday Agreement, most vote transfers occurred within Loyalist or Republican communal blocs; "the level of cross community transfers was low" (Elliot, 2003). ${ }^{4}$ Where protracted violent conflict has occurred, even moderate voters all too regularly gravitate towards those offering a hard-line assertion of ethnic interests.

Horowitz's case for AV, as reformulated on the new assumption of "mild" preference schedules, might therefore reasonably be discounted for post-civil warfare situations (like Bosnia, Northern Ireland, Afghanistan or Iraq) and instead reserved solely for those countries where voting is along ethnic lines but where inter-ethnic friction has never spilled over into armed conflict, or to countries that subsequently become less polarized. Yet even in such milder situations, the anticipated centripetal operation of AV may be disrupted if a substantial number of voters respond to the diminishing electoral significance of ethnicity by emphasizing other, non-ethnic, dimensions to the political process (generating non-singlepeaked preferences).

\footnotetext{
${ }^{3}$ This is the first time Horowitz has acknowledged that his theory is "premised ... on the willingness of voters to cast second and subsequent preferences interethnically even before all intraethnic choices are exhausted" (Horowitz, 2004:510). In his book on South Africa, Horowitz considered the possibility of "severe" schedules and proposed a compulsory ballot to force voters to express inter-ethnic preferences (much the same reasoning as inspired Fiji's 1995-96 Constitutional Review Commission); “ . . even if voters are not prepared easily to contemplate crossing ethnic lines, that is not an insurmountable problem, because second or third preferences could be made compulsory for a valid ballot" and, further on in the same chapter, he said that "a defect of the [Sri Lankan] system is that second preferences are not required for a valid ballot" (Horowitz, 1991:190, 192). This strongly implies that, at least for Sri Lanka, he earlier acknowledged the likelihood of hard-line, rather than the currently posited softer-line, preference schedules.

4 "Nationalist voters in the SDLP are strongly more likely to give their lower order votes to Sinn Fein before the UUP, and UUP voters are strongly more likely to give their lower order preferences to the DUP before the SDLP. Only small numbers cross the ethno-national frontier at all...." (Brendan O'Leary, personal communication, August 14, 2005).
} 
Horowitz has claimed that $\mathrm{AV}$ "will provide some moderate boost to the moderate middle, on whatever issues emerge, at the expense of the extremes" (1991:197). ${ }^{5}$ But, as we have shown, all roads do not lead to Rome: the appearance of alternative political focal points unrelated to those dictated by ethnic allegiances strengthens the potential for alliances (and/or vote transfers) between strange bedfellows; "ins" versus "outs," personality-specific deals, regionally-based accords or left against right or other lines of political association (Fraenkel \& Grofman, 2004:499). There is no compelling reason why usage of AV in contexts with such conflicting lines of allegiance should encourage preference transfers towards some multi-dimensional moderate center.

Horowitz claims that "the coalition of extremes of two divergent ethnic groups is not a likely outcome under AV in a severely divided society" (Horowitz, 2004:511). Yet this only indicates a misleading identification of preference transfers with "coalitions" (or even of the exchange of preference votes between parties with the building of one of those "coalitions of commitment" that he favorably contrasts with "coalitions of convenience" forged by parties in parliament after elections). ${ }^{6}$ Opposition parties may find it difficult to reach agreements among themselves on policies or formal alliances, but they need no such accords to put incumbent parties as last preference. In a compulsory voting system with a fractionalized party setting, this may reward those parties placed in penultimate positions. ${ }^{7}$ Such vote transfer-driven coalitions-by-default between opposites are much less likely under optional AV systems of the type used in some of the postwar Canadian provinces or in single seat Irish by-elections (cf. Jansen, 2004; Punnett, 1986).

Third, Horowitz (2004:510) suggests that the AV system may induce strategic adjustments to voter preferences. If extremists from the majority ethnic group look like winning a particular constituency, moderates from the minority ethnic group may choose to back moderate candidates from the majority group rather than their own extremists who have no chance of winning. But this logic of voting strategically so as to attempt to avert having one's worst case outcome applies to voter incentives in all majority-plurality systems, including even the two round systems Horowitz emphatically condemns for reinforcing bipolar cleavages in presidential elections in Benin. ${ }^{8}$ As Lijphart points out, under simple plurality (or firstpast-the-post) systems, larger parties appeal to voters not to waste votes on smaller parties.

\footnotetext{
${ }^{5}$ Having considered the possibility that ethnicity might turn out not to be the critical issue in post-Apartheid South Africa, Horowitz argued that AV "will still encourage conciliation along whatever lines of difference emerge in the polity - including, but not limited to, differences based on policy, ideology, class or region. Consequently, to adopt these innovations is ... only to take some precautions against severe polarization of any kind" (Horowitz, 1991:197).

${ }^{6}$ This is a critical part of Horowitz's claims regarding the benefits of vote-pooling arrangements (like STV and AV) as opposed to proportional representation-based electoral systems (Horowitz, 1985:369-395). Yet there seems little logical reason to accept the claim that the type of bargaining arrangements required to make deals about swapping preferences votes are somehow more robust (in the sense of entailing real commitments to policy compromise over ethnically divisive issues) than those made between political parties seeking to form a government.

${ }^{7}$ Precisely this kind of tactic sealed the fate of Fiji's governing party and its coalition allies at the 1999 polls, despite their having cooperated to introduce the reformist 1997 constitution along with the alternative vote system. Fijian extremist opponents of the new constitution gave penultimate preferences to the mainly Indian-backed Fiji Labour Party in key marginal constituencies - with the aim of ousting the then current government from office.

8 "Some [divided societies] have crafted counterproductive provisions, such as Benin's presidential runoff, modelled on France's, which converted a fluid tripolar conflict into a more dangerous bipolar one" (Horowitz, 2000:10). But, might not AV, used either in legislative or presidential elections in a bipolar society, similarly draw heterogeneous political parties into a bitter two party communal contest for control over the state?
} 
Under AV, smaller parties are more likely to stand candidates, with like-minded larger parties making appeals for second or lower preferences. According to Lijphart, both systems possess "exactly the same incentives to compromise" (Lijphart, 1991:93-94).

Strategic voting under AV is a complex business; outcomes can vary depending on the exact order of elimination of parties and there may be incentives for additional parties to form (cf. Duverger, 1959; Cox, 1997). Where there are more than four parties, strategic voting becomes still more difficult to fathom. If there is more than one dimension to the political process, and thus some proportion of non-single-peaked preferences, strategic voting becomes even more tricky. Horowitz suggests that if moderate voters behave strategically, or if they have "mild" preferences, our case 2 no longer results in victory for a radical party. In our case 2 , he claims, "moderate voters of the smaller group, knowing that the moderate candidate of the larger ethnic group will not survive the third count, nevertheless do nothing to prevent the victory of their extremist antagonist" (2004:510).

\section{Case 2}

\section{Preferences}

\begin{tabular}{llll}
\hline $\mathrm{rF}$ & $\mathrm{mF}$ & $\mathrm{mI}$ & $\mathrm{rI}$ \\
$\mathrm{mF}$ & $\mathrm{rF}$ & $\mathrm{rI}$ & $\mathrm{mI}$ \\
$\mathrm{mI}$ & $\mathrm{mI}$ & $\mathrm{mF}$ & $\mathrm{mF}$ \\
$\mathrm{rI}$ & $\mathrm{rI}$ & $\mathrm{rF}$ & $\mathrm{rF}$
\end{tabular}

Count

\begin{tabular}{llll}
\hline & 1 & 2 & 3 \\
\hline $\mathrm{rF}$ & 40 & 40 & 60 \\
$\mathrm{mF}$ & 20 & 20 & excl \\
$\mathrm{mI}$ & 30 & 40 & 40 \\
$\mathrm{rI}$ & 10 & excl & \\
\hline
\end{tabular}

In fact, this makes no difference whatsoever to the outcome. Only if supporters of the minority radical party (rI) eschew giving a 2nd preference to the moderate party of their own ethnic group $(\mathrm{mI})$ and give this instead to the moderate party of the other ethnic group $(\mathrm{mF})$ might the victory of the majority radical party $(\mathrm{rF})$ be avoided. But this would involve more than strategic avoidance of "no hope" candidates. It entails abandoning a well-placed centrist party from one's own ethnic group based upon accurate pre-election anticipation both of the overall distribution of first preference support and of prevalent rankings by other voters (i.e., a non-single-peaked preference). Such adjustments are unlikely in real world settings.

Our cases were intended to illustrate theoretical possibilities, not (as Horowitz seems to believe) to model actual behavior in divided societies. Case 2 was simply intended to show that, even without majority first preference support for extremist parties, a radical party could emerge victorious in a four party, single-peaked, setting where no party obtains a first count majority. Conversely, case 3 showed that even in the presence of an anti-moderation first preference majority, a moderate victory was logically possible, although only on the basis of 
"rather severe distributional assumptions" (Fraenkel \& Grofman, 2004:495). Horowitz responds favorably to case 3 merely on the grounds that it shows a moderate victor (2004:511), ${ }^{9}$ but this misses the key point. As we indicated, only a very trivial modification of case 3 results in defeat for the moderate party backed by the median voter and transforms the final count contest into one pitting the two radical parties against one another. ${ }^{10}$

Case 3 in Fraenkel and Grofman (2004) modified by one change in preference-ranking

\section{Preferences}

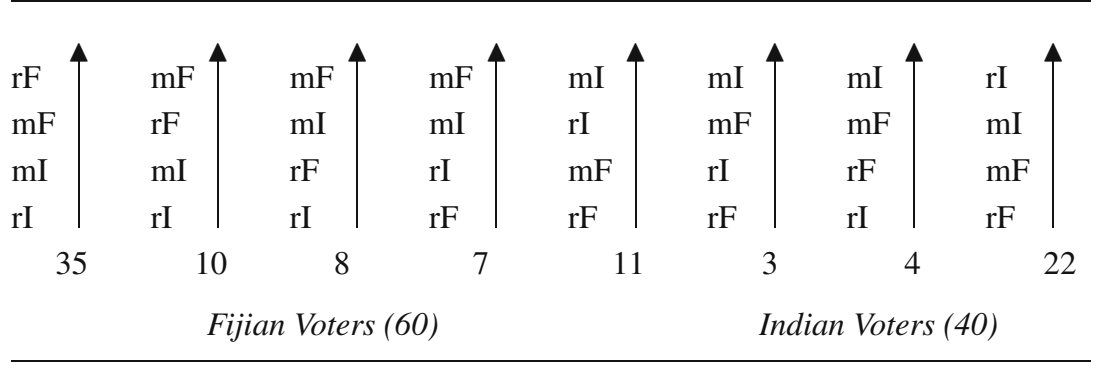

The Count

\begin{tabular}{llll}
\hline & 1 & 2 & 3 \\
\hline $\mathrm{rF}$ & 35 & 35 & 57 \\
$\mathrm{mF}$ & 25 & 32 & excl \\
$\mathrm{mI}$ & 18 & excl & - \\
$\mathrm{rI}$ & 22 & 33 & 43 \\
\hline
\end{tabular}

Notes. Fraenkel and Grofman (2004:497) case 3 modified by assuming that 11 (rather than 10) voters back $\mathrm{mI}, \mathrm{rI}, \mathrm{mF}, \mathrm{rF}$, and 3 (rather than 4) voters back $\mathrm{mI}, \mathrm{mF}, \mathrm{rI}, \mathrm{rF}$. Everything else remains identical

Now we turn to more general points.

First, Horowitz responds to our claim that AV does not "necessarily" or "uniformly" favor moderate parties not on the grounds that we are wrong, but by suggesting that he has never claimed that it does $(2004: 507,509 ; 2006: 653)$. He now very selectively cites himself saying pro-moderation outcomes are "likely to," "may" and even "generally" occur under AV (2006:654n; 2004:507, 509). Yet, in other passages, Horowitz has regularly embraced a much more determinist language regarding AV's moderation-inducing virtues, as shown in the quotes below (emphases added in all cases): ${ }^{11}$

\footnotetext{
${ }^{9}$ Notably also, case 3 (even in its unmodified form) met Horowitz's favored requirements of having some "mild" schedules and/or strategic voting.

${ }^{10}$ For empirical examples of this kind of outcome, see our analysis of the Fiji elections in 2001 (Fraenkel \& Grofman, 2006a, Figure 5).

${ }^{11}$ What Horowitz regularly suggests is an overall pro-moderation impetus associated with AV, coupled with some, less powerful, incentives for flank parties to form. He nowhere acknowledges the possibility of a national-level outcome that does not favour moderates.
} 
- $\mathrm{AV}$ is "an electoral system that will make moderation rewarding by making politicians reciprocally dependent on the votes of members of groups other than their own. The dependence is only marginal, of course, but it will sometimes be the margin of victory. Since parties must pool votes rather than pool merely seats, they must find ways before the election to communicate their ethnically and racially conciliatory intentions to voters. After the election, they must deliver on those commitments or risk electoral retribution" (Horowitz, 1991:196);

- "[b]ecause of the need for inter-party agreements to exchange votes, there would be a pull towards the center of the system that would help counter polarization." (1991:202);

- "[AV's] incentives are effective because those votes will not be forthcoming unless the candidates receiving them can be portrayed as moderate on interethnic issues. Consequently, any compromises achieved at the top will be supported by electoral incentives at the bottom" (Horowitz, 1997:24-25);

- "Where electoral rewards are present ... [t]he electoral rewards provided to the moderate middle compensate for the threat posed by opposition from those who can benefit from the aversion of some group members to inter-ethnic compromise (Horowitz, 2002:23);

- "The alternative vote ... favors moderates" (Horowitz, 2003:122).

In these passages, there is little sign of the now preferred emphasis on the contingency and uncertainty of moderation inducing pressures under AV. And, indeed, despite now acknowledging that "there are no good predictors of the incidence of moderate outcomes under AV," Horowitz continues to advise divided societies to "follow the odds" by adopting AV (Horowitz, 2006:660).

Second, Horowitz turns for support to what he calls "the more-or-less universally held view that AV generally fosters moderate results" (2006:653; 2004:412), and claims that the Australian, PNG and Fiji experiences support these conclusions (2004:512-3). But this view is not in fact that widely held. Lijphart (1991:95; cf. 1997), for example, questions "the dubious claim that AV induces moderation," while Sisk (1996:44) doubts whether "politicians will respond to the $[\mathrm{AV}]$ incentive structure, if it exists." In Sri Lanka, where a variant on the alternative vote system is used in elections for the presidency, Tamils have repeatedly chosen to boycott elections rather than backing the election of "moderate" Sinhalese leaders (Reilly, 2001:118-124; Economist 24th November 2005). ${ }^{12}$ In Fiji, both major communities participated at the polls in 1999 and 2001, but the 1999 results saw the defeat of the inter-ethnic coalition that had compromised to introduce the new reformist constitution (and the associated AV system) followed by a coup d'etat a year later (Fraenkel, 2001a,b). In 2001, as Horowitz himself now accepts (2006:58-9), the outcome did not favor interethnic moderates. ${ }^{13}$ In the May 2006 Fiji election, moderates fare more poorly than ever, and nearly all the seats were

\footnotetext{
${ }^{12}$ In Sri Lanka's presidential elections, all but the top two candidates are immediately eliminated if no majority is secured at the first count. Horowitz has regularly argued that the moderation-inducing potential of Sri Lanka's electoral system remains untested, owing to Tamil boycotts (Horowitz, 1985:639-643; 1989: 4). Yet, since the theory now rests on behavioural assumptions about the willingness of voters to back moderates from the other ethnic group, one might legitimately respond that Tamils, faced with the choice of whether or not to back one or other of the main Sinhalese leaders (instead of electing their own leaders), declined to participate.

13 We avoid covering Horowitz's points about the Fiji data here, since these are dealt with in some detail elsewhere (see Fraenkel \& Grofman, 2006a,b).
} 
divided between the two large parties, one based in the Fijian and the other in the Indian community. ${ }^{14}$

Horowitz suggests that the 1975 shift from AV to first-past-the-post was responsible for Papua New Guinea's post-independence "upsurge in interclan violence," "recurrent victories on small clan-based pluralities" and "government instability" (Horowitz, 2004:513; 2006:653). In fact, (i) the resurgence of tribal fighting in the PNG highlands after independence (if that ever truly ended) was connected with the end of colonial policing (via the kiap system) rather than the electoral system change (Ketan, 2004:60-61; Dinnen, 1998:49). (ii) Fractionalization of electoral support, again particularly in the highlands, was primarily due to the high degree of ethnic (or clan) heterogeneity in PNG and the absence of sufficiently strong national-level ideological cleavages to facilitate the emergence of a robust political party-based system. (iii) Regular post-independence changes in government, due to shifting M.P. allegiances and "no confidence" votes, were not the result of electoral incentives, but were symptomatic of highly competitive post-independence political cultures (Fraenkel \& Grofman, 2005; Fraenkel, 2005). The claim that the reintroduction of AV will "revive accommodative politics" is questioned by many PNG politics specialists (cf. Standish, 2002:28, 31; May, 2006:14; May, 2003:7). Few reformers within the country have much confidence in the ability of electoral system change to diminish political instability, which is why they have simultaneously introduced an Organic Law on the Integrity of Political Parties and Candidates to prevent floor-crossing and to tie MPs more firmly to political parties (Baker, 2005; Gelu, 2005; Okole, 2005).

In Australia, where AV has been used for federal elections since 1918, it is regularly claimed that the electoral system "pushes politics towards the center" (Reilly, 2001:42-57). Yet this claim is made without much in the way of supporting empirical investigation. Some specialists have also queried these claims. Wright (1986:135) concludes that despite "much talk among politicians about the desirability of cooperation in the national interest, ... the [Australian] single member district systems undoubtedly encourage a confrontational style of politics." Sharman, Sayers and Miragliotta show that preference trading relationships in AV elections responded to numerous motivations, including "hostile," "discriminatory" and "punishing" types, and argue that AV generally favors larger parties as against smaller parties with geographically dispersed support (2002:548, 544). Sharman (personal communication, August 10, 2005) argues that " $\mathrm{AV}$ is a majoritarian system designed to create parliamentary majorities so, while bargaining may take place in the electoral forum, there is no incentive for compromise over government policy once a party or coalition is in office.... There is no reason at all why AV should lead to moderation in public policy. ... Moderation in Australian public policy - such as there is - derives from its tradition of strong parliamentary bicameralism and the operation of a federal dispersal of power."

We do, however, accept Horowitz's point (2004:512-3) that "Australian AV produces coalitions with ideological affinity" and that there is "no evidence of coalitions of opposites" of the type seen in Fiji in 1999. ${ }^{15}$ This, however, has much to do with the prevailing two (or two and a bit) party system in Australia, and generally single-peaked preference orderings. With multiple opposition parties ranged across the political spectrum and non-single-peaked preferences, alliances of "outs" versus "ins" become much more likely.

\footnotetext{
${ }^{14}$ The only exceptions were in those seats where neither Fijians, nor Indians, vote (i.e., the so-called 'General Voters' constituencies), and in the constituency allotted to those from the island of Rotuma, to the far northwest of the Fiji group.

${ }^{15}$ See footnote 7 above.

Springer
} 


\section{Discussion}

Even if AV were shown to encourage centrist parties or candidates in Australia, this would provide no greater support for Horowitz's case for AV in Fiji, South Africa, or Bosnia, than applying the often heard claims (based on the theoretical ideas of the economist Anthony Downs) that plurality systems favor moderation in Britain or America to argue for use of plurality-based voting in deeply divided societies. Horowitz's own starting point was, quite rightly, to advise that electoral/constitutional strategies be tailor-made for plural societies (1985:576; 1991:198-99). Electoral laws are "embedded institutions," which operate in strikingly different ways in different settings (Grofman, 1999; Bowler \& Grofman, 2000; Fraenkel \& Grofman, 2005:269).

Similarly, debates about the virtues of AV as compared to simple plurality systems in the US or Britain raise different questions to those at issue in discussions about alternative electoral systems in divided societies. In the U.S., AV (under the name instant runoff) has been urged by electoral reformers in part because of its greater propensity (as compared to simple plurality) to pick Condorcet winners. For four parties or candidates (or fewer), if preferences are single-peaked and voting is sincere, as Grofman and Feld show, AV is "always as likely or more likely to select the Condorcet winner than plurality," although this result does not hold if there are more than four alternatives $(2004: 647,649)$. In the U.S., the alternative vote has also been urged on the grounds that, unlike plurality, it permits voters to express their "true" preferences for candidates who, in terms of first place preferences, have little chance of being the plurality winner. It arguably can do this without simultaneously creating an increased likelihood that the voter's least preferred candidate will gain victory. But these concerns are raised in the context of the Anglo-American mass democracies where the alternatives under discussion are usually AV versus simple plurality, not, as is more frequently the case in deeply divided societies, majoritarian versus proportional systems.

Our investigations have suggested three broad types of outcome under AV in bipolar countries with fractionalized party settings (and we do not discount the possibility of others, particularly in multi-polar settings). One is the Horowitzian centripetal movement of preferences towards the moderate center, either because (a) there is already a first count moderate majority or (b) those that support small radical parties tend to transfer votes to moderate parties from their own ethnic group or (c) because moderates transfers votes inter-ethnically. A second is a centrifugal movement away from the moderate center, either because (a) the first preference vote for radicals is so much more substantial than that for moderates and/or (b) because moderate voter preferences are "severe." A third alternative is the non-single-peaked scenario, in which vote transfers no longer tend to move from ethnic extremists to moderates. In such situations, outcomes potentially become highly erratic; preference swapping arrangements may be driven by "outs" versus "ins" accords, local personality-specific deals, regional alliances, tactical exigencies or by ties based on distinct ideological convictions. In either of the latter two highly plausible and empirically realized scenarios, Horowitz's claims about the moderation inducing features of AV fail to hold. That is the central point in Fraenkel and Grofman (2004), and nothing Horowitz has written since in any way rebuts it.

\section{References}

Baker, L. (2005). Political Integrity Laws in Papua New Guinea and the Search for Stability. Pacific Economic Bulletin, 20(1).

Black, D. (1958). The theory of committees and elections. New York: Cambridge University Press. 
Bowler, S., \& Grofman, B. (2000). Introduction. In: S. Bowler, \& B. Grofman (Eds.), Elections in Australia, Ireland and Malta under the single transferable vote (pp. 1-14). Ann Arbor, Michigan: University of Michigan Press.

Cox, G. (1997). Making votes count: Strategic coordination in the World's electoral systems. Cambridge: Cambridge University Press.

Duverger, M. (1959). Political parties, their organization and activity in the modern state (Translated by Barbara and Robert North) (2nd edition). New York: Wiley.

Dinnen, S. (1998). Weakness and strength - state, society and order in Papua New Guinea. In: P. Dauvergne (Ed.), Weak and strong states in Asia-Pacific societies (pp. 38-59). Allen \& Unwin \& ANU.

Elliot, S. (2003). North Vote sees over 80 per cent of Transfers Stay within Party. Irish Times.

Fraenkel, J. (2000). The triumph of the non-idealist intellectuals? An investigation of Fiji's 1999 election results. Australian Journal of Politics and History, (46), 1.

Fraenkel, J. (2001a). The alternative vote system in Fiji; electoral engineering or ballot-rigging? Journal of Commonwealth and Comparative Politics, 39(2), 1-31.

Fraenkel, J. (2001b). The clash of dynasties and the rise of demagogues; Fiji's Tauri Vakaukauwa of May 2000. Journal of Pacific History, 35(3).

Fraenkel, J. (2005). The political consequences of Pacific Island electoral laws. SSGM, ANU, Discussion Paper http://rspas.anu.edu.au/papers/melanesia/discussion_papers/05_08_dp_fraenkel.pdf.

Fraenkel, J., \& Grofman, B. (2004). A Neo-Downsian model of the alternative vote as a mechanism for mitigating ethnic conflict in plural societies. Public Choice, 121(3-4), 487-506.

Fraenkel, J., \& Grofman, B. (2005). Editor's introduction: Political culture, representation and electoral systems in the Pacific Islands. Commonwealth and Comparative Politics, 43(3), 261-275.

Fraenkel, J., \& Grofman, B. (2006a). Does the alternative vote foster moderation in ethnically divided societies? The case of Fiji. Comparative Political Studies, 39(5), 623-651.

Fraenkel, J., \& Grofman, B. (2006b). The failure of the alternative vote as a tool for promoting ethnic moderation in Fiji: A reply to Horowitz. Comparative Political Studies, 39(5), 663-666.

Gelu, A. (2005). The failure of the organic law on the integrity of political parties and candidates (OLIPPAC). Pacific Economic Bulletin, 20(1), 83-97.

Grofman, B. (1999). Preface: Methodological steps toward the study of embedded institutions. In: B. Grofman, S.-C. Lee, E. Winckler, \& B. Woodall (Eds.), Elections in Japan, Korea and Taiwan under the single non-transferable vote: The comparative study of an embedded institution (pp. ix-xvii). Ann Arbor, MI: University of Michigan Press.

Grofman, B., \& Feld, S. L. (2004). If you like the alternative vote (a.k.a. the instant runoff), then you ought to know about the Coombs rule. Electoral Studies, 23, 641-659.

Horowitz, D.L. (1985). Ethnic Groups in Conflict. Berkeley: University of California Press.

Horowitz, D.L. (1989). Incentives and behaviour in the ethnic politics of Sri Lanka and Malaysia. Third World Quarterly, 10(4), 18-35.

Horowitz, D.L. (1991). A democratic South Africa? Constitutional engineering in a divided society. Berkeley: University of California Press.

Horowitz, D.L. (1997). Encouraging electoral accommodation in divided societies. In: B.V. Lal, \& P. Larmour (Eds.), Electoral systems in divided societies: The Fiji constitutional review. Canberra: ANU.

Horowitz, D.L. (2000). Some realism about peacemaking. Paper delivered at the conference "Facing Ethnic Conflicts" Center for Development Research: Facing Ethnic Conflicts, Bonn, 14-16 December 2000, pp. $1-17$.

Horowitz, D.L. (2002). Constitutional design: Proposals versus process. In: A. Reynolds (Ed.), The architecture of democracy; Constitutional design, conflict management and democracy (pp. 15-36). Oxford: Oxford University Press.

Horowitz, D.L. (2003). Electoral systems: A primer for decision makers. Journal of Democracy, 14(4), 115127.

Horowitz D.L. (2004). The alternative vote and interethnic moderation: A reply to Fraenkel and Grofman. Public Choice, 121(3-4), 507-516.

Horowitz, D.L. (2006). Strategy takes a holiday. Comparative Political Studies, 39(5), 652-662.

Jansen, H.J. (2004). The political consequences of the alternative vote: Lessons from Western Canada. Canadian Journal of Political Science, 37(3), 647-669.

Ketan, J. (2004). The name must not go down; Political competition and state-society relations in Mount Hagen, Papua New Guinea. Suva: Institute of Pacific Studies, USP.

Laponce, J.A. (1957). The protection of minorities by the electoral system. The Western Political Quarterly, $10(2), 318-339$.

Lijphart, A. (1991). The alternative vote: A realistic alternative for South Africa? Politkon, 18(2), 91-101. 
Lijphart, A. (1997). Disproportionality under alternative voting: The crucial - and puzzling - case of the Australian Senate Elections, 1919-1946. Acta Politica, 32(1), 9-24.

May, R. (2003). Disorderly democracy: Political turbulence and institutional reform in Papua New Guinea, state, society \& governance in Melanesia. Discussion paper, 2003/3.

May, R. (2006 forthcoming) Political parties in Papua New Guinea. In: R. Rich, L. Hambly, \& M. Morgan (Eds.), Political Parties in the Pacific Islands. Canberra: Pandanus Press.

Okole, H. (2005). The fluid party system in Papua New Guinea. Commonwealth \& Comparative Politics, 43(3), 362-381.

Punnett, R.M. (1986). The alternative vote with optional use of preferences: Some Irish Lessons for Britain and Australia. Journal of Commonwealth and Comparative Politics, xxiv, 1.

Regenwetter, M., Grofman, B., Marley, A.A.J., \& Tsetlin, I. (2006). Behavioral social choice: Probabilistic models, statistical inference, and applications. New York: Cambridge University Press.

Reilly, B. (2001). Democracy in divided societies; Electoral engineering for conflict management. Cambridge: Cambridge University Press.

Sharman, C., Sayers, A.M., \& Miragliotta, N. (2002). Trading party preferences: The Australian experience of preferential voting. Electoral Studies, 21, 543-560.

Sisk, T. (1996). Power sharing and international mediation in ethnic conflict. Washington, D.C: United States Institute of Peace.

Standish, B. (2002). Papua New Guinea politics: Attempting to engineer the future. Development Bulletin, 60, 28-32.

Wright, J.F.H. (1986). Australian experience with majority-preferential and quota preferential systems. In: B. Grofman, \& A. Lijphart (Eds.), Electoral laws and their political consequences (pp. 124-138). New York: Agathon Press. 